\title{
Development and Evaluation of a Groundnut In-Shell Grader
}

\author{
Adepoju B. Fashina1, Aminu Saleh², Fatai B. Akande1 \\ ${ }^{1}$ Department of Agricultural Engineering, Ladoke Akintola University of Technology, Ogbomoso, Nigeria \\ ${ }^{2}$ National Centre for Agricultural Mechanization, Ilorin, Nigeria \\ Email: fbukkyakande@yahoo.com
}

Received 26 January 2015; accepted 9 February 2015; published 15 February 2015

Copyright (C) 2015 by authors and Scientific Research Publishing Inc.

This work is licensed under the Creative Commons Attribution International License (CC BY).

http://creativecommons.org/licenses/by/4.0/

c) (i) Open Access

\begin{abstract}
Groundnuts marketed from farms are generally referred to as groundnuts in-shell. When freshly harvested, they may contain some dirt, vines and other foreign materials. Grades of these stocks are established based on intended use. Groundnut producers and commercial buyers use the grade as guidelines for trading. Grading aims at raising the quality and value of the product. Grading is generally limited to measurement of physical properties, such as, size distributions of the pods and percentage by weight of shelled kernels in the undecorticated groundnuts and percentage by weight of foreign materials. A groundnut grader was designed and developed. It was designed to sort three selected groundnut varieties commonly cultivated in Nigeria into three grades based on the geometric dimensions of the selected varieties. These varieties are SAMNUT 10, 14 and 18. Analyses of grading trials indicate that while SAMNUT 10 exhibits the three grades, the other varieties (SAMNUT 14 and 18) can only be graded into two grades. The grader has a rated capacity of grading 224 th$^{-1}$ of under corticated pods. The maximum ranges within each grade when all the varieties were considered were: grade I-15.81 $\mathrm{mm}$ to $18.05 \mathrm{~mm}$, grade II-12.44 $\mathrm{mm}$ to $15.78 \mathrm{~mm}$ and grade $\mathrm{III}-10.60 \mathrm{~mm}$ to $13.30 \mathrm{~mm}$.
\end{abstract}

\section{Keywords}

Groundnut In-Shell, Grading, Geometric Dimensions

\section{Introduction}

Groundnut (Arachishypogaea L.) processing and trade are major sources of employment, income and foreign exchange in many West African countries. Groundnut products are of central economic importance to millions of smallholders in the region, generating much of the rural cash income and accounted for higher rural labour 
force in the sub-region [1]. Groundnut has immensely contributed to the economic development of Nigeria being one of the most popular commercial crops. Nigeria produces $41 \%$ of the total groundnut production in West Africa.

Groundnut grading and handling procedures dated back to the 1960s when it was established for the marketing quota groundnut programme in the United States. Grading is the process of sorting of a given product according to the stipulated categories. The aim of grading is to maintain the quality of the product by removing all destructive elements by the sorting of the homogenous lots of the produce according to the fixed grade standards [2]. It is thus being referred to as classification on the basis of their commercial values and usage. Grading procedures to be used by farmers depend on the target market specifications and requirements [3]. Agricultural products may be graded either on the basis of their physical characteristics, chemical or biological properties. Physical characteristics include size, weight, moisture content, texture, colour, shape and foreign matter. Chemical properties may either be the analysis of the composition of the product, its rancidity or colour. Biological properties refer to the type and amount of mould damage, insect damage or germination percentage of the product. Generally, grading by size and weight are the most widely adapted methods [3]. Weight graders are used when grading products by weight while size graders use sieves or diverging belts or bars.

Agricultural produce are generally graded in accordance with the various quality factors. Grading of groundnut is beneficial to the farmers, traders as well as to the consumers in the sense that it increases the quality and value of the product. Since groundnut is mainly used for oil extraction, the quality of pods is therefore, judged by certain factors which yield the quality. There are other factors which have a direct bearing on the yield and quality of the oil obtained. These include size, colour, nature of damage of kernels, impurities and moisture content. Manual grading is archaic, expensive, and time-consuming and fails to provide an adequate measure of quality at each stage marketing the produce.

Graded products must be free from insects, sour and undesirable odours. Quality groundnut should not also contain any substance which renders them unfit for consumption and processing. These parameters are used to establish the grade that determines its commercial value. Generally, the problems associated with grading include time consumption, high cost, crop destruction and sometimes as an inaccurate measure of quality determination [3]. When groundnuts in-shell are graded, farmers can sell according to the sizes of groundnut in-shell. Also buyers will have confidence in the farmers and the products purchased. This is the main objective of this paper.

\section{Methodology}

\subsection{Determination of Physical Properties of Groundnut}

To construct the grading sieves, physical properties of the groundnut in-shell were determined. These properties include; shape, size, and moisture content. One hundred pods each were randomly selected from the three varieties. It was considered that this number would be adequate to give the sample mean that would be very close to the entire population mean. These samples dimensions were measured with precision digital vernier calipers that would measure to the nearest 0.01 .

The principal axes (sizes) of the groundnut pods considered were: the length 1), major width 2) and thickness 3) of the groundnut pods as suggested by [4]); [5]-[7]. These were used to calculate the various aperture sizes of the decorticating and grading screens as suggested by [4] [8].

\subsection{Description of the Groundnut Grader}

From the results of physical properties of the selected groundnut varieties determined in 2.1, a groundnut grader was designed and constructed. It consist of two oblong slotted oscillating sieves, a collection tray, an eccentric mechanism and an angle iron frame of $50 \times 50 \times 5 \mathrm{~mm}$ dimensions (Figure 1). Its maximum height was 810 $\mathrm{mm}$. The oscillating sieves have slot sizes of $16 \mathrm{~mm} \times 50 \mathrm{~mm}$ and $13 \mathrm{~mm} \times 50 \mathrm{~mm}$ respectively that is oscillated by an eccentric mechanism. The crank assembly is capable of giving a stroke of $25 \mathrm{~mm}$. The grader classifies groundnuts in-shell into three distinct grades according to size. A schematic illustration of the Groundnut in-shell grader is shown in Appendix I.

\subsection{Principle of Operation of the Groundnut Grader}

The grader achieves classification of the whole in-shell nut according to particle size. Groundnuts in-shell was fed 


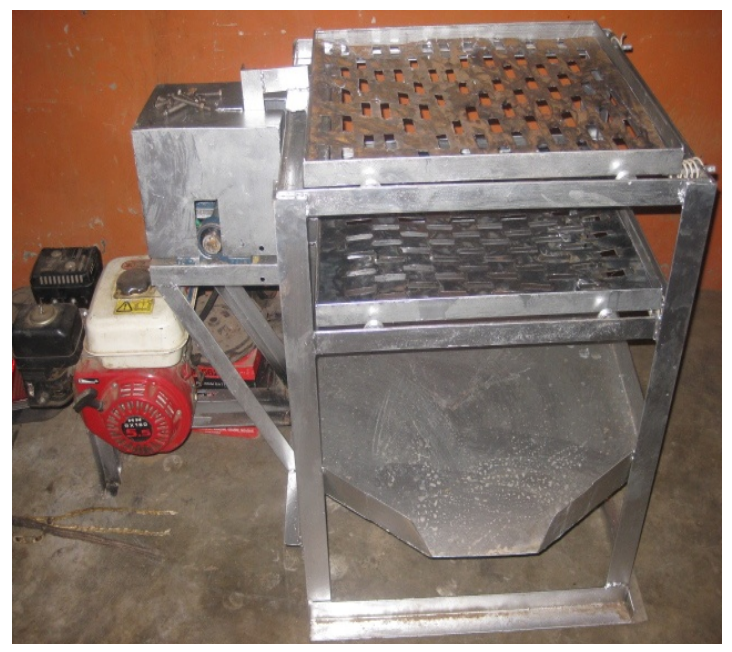

Figure 1. Groundnut in-shell grader.

into the grader through the upper sieve that also serves as the hopper. The pods travel towards the lower part of the grader by gravity through the perforated sieve that was greater than its major diameter and drops into the lower sieve for further grading. The pods with major diameter larger than the sieve diameter were retained on the sieve. It thus allows evenly kernels through the shaking sieve into the collecting trays that were fitted at the front of the grader. The pods that are retained on a particular tray determine its grade.

\subsection{Performance Test and Evaluation of Groundnut Grader}

Two methods of grading were considered feasible. These are either grading by size or weight. It was also reported that groundnut in-shell lies on the grading sieve along the XX-axis during decortication (Figure 2), grading groundnut in-shell by their size along YY-axis (pod's major diameter) appears to be a logical approach.

\section{Results and Discussion}

\subsection{Results of Geometric Sizes of Groundnut in-Shell}

The values of the geometric dimensions of the samples of groundnut in-shell under consideration are determined. An analysis of the results by measure of central tendency shows the means and standard deviations of the length and width (major diameter) of the three selected varieties of the groundnut in-shell (Table 1). The analysis shows that Samnut 10 has the greatest mean length of $33.33 \mathrm{~mm}$ followed by Samnut 18 with $30.01 \mathrm{~mm}$ while Samnut 14 has the least value of $25.89 \mathrm{~mm}$. The means and standard deviations of width of the respective varieties show Samnut 18 having the largest of 15.11 mm, Samnut 10 with 14.34 and 13.44 mm for Samnut 14.

\section{Goodness of Fit for Distribution of Dimensions of the Selected Groundnut Varieties}

Before any valid assumption could be made on the data collected concerning the geometric dimensions of the selected groundnut varieties, the data should conform to the rules of normal distribution [9]. The frequency distribution curves for the values of the length and width dimensions of the selected groundnut varieties are shown in Figure 3 and Figure 4. The varieties considered exhibit normal distribution. The length and width of Samnut 14 and 18 varieties did not show much variation from their respective means except those of Samnut 10. However, the peaks of all their curves correspond to the respective values of their means. The curves of Samnut 14 and Samnut 18 are also noticed to be narrower and higher than those of Samnut 10. This suggests that a greater percentage of their length and width dimensions are closer to their corresponding means than those of Samnut 10 whose curve widens. The widening curves of Samnut 10 indicated uneven size distribution and its possible spread in all the grades to be determined.

Examining these data (major diameter), it was observed that when all the data for all the varieties were pooled together, their range falls between $10.94 \mathrm{~mm}$ and $17.98 \mathrm{~mm}$. The range chosen is $10-18 \mathrm{~mm}$. The three grades chosen were: 16.00 - 18.99 mm for grade I, 13.00 - 15.99 mm for grade II, while grade III ranges from 10.00 - 


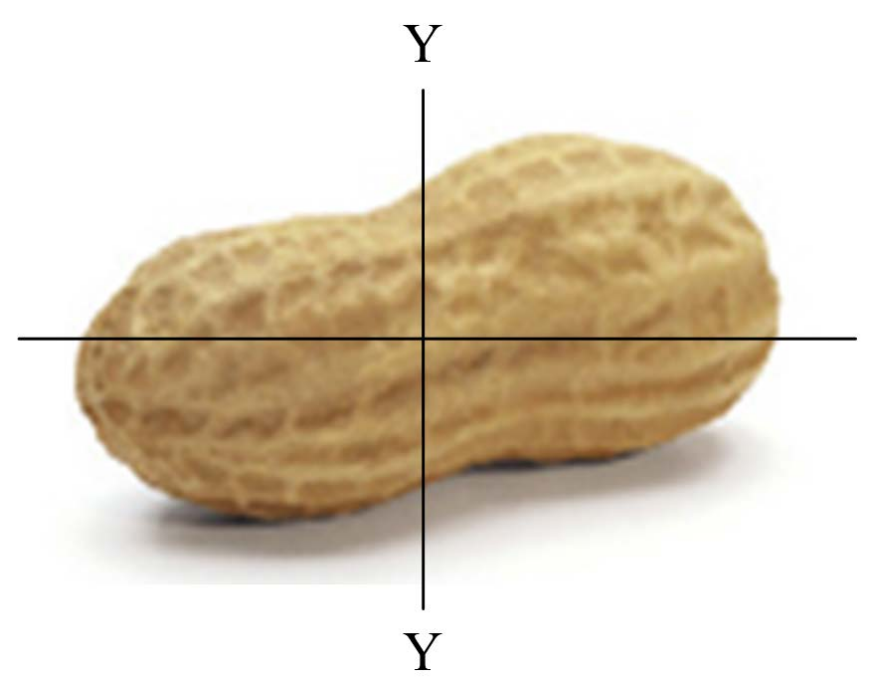

Figure 2. Axial dimensions of the groundnut in-shell.

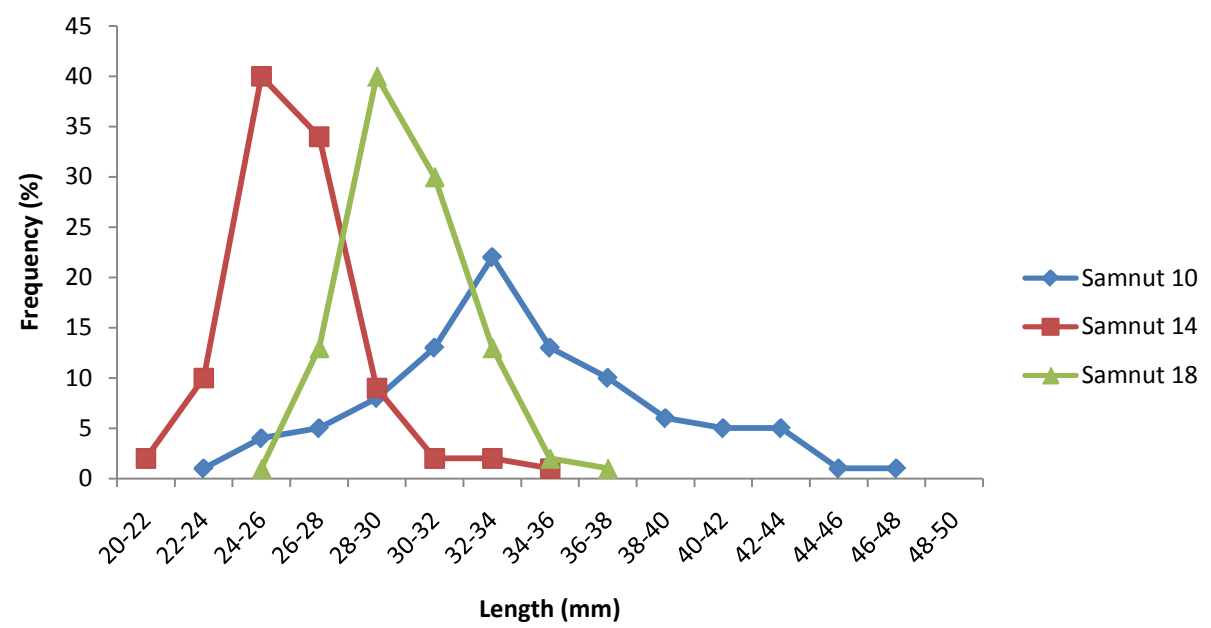

Figure 3. Frequency distribution curve for the lengths of the selected groundnut varieties.

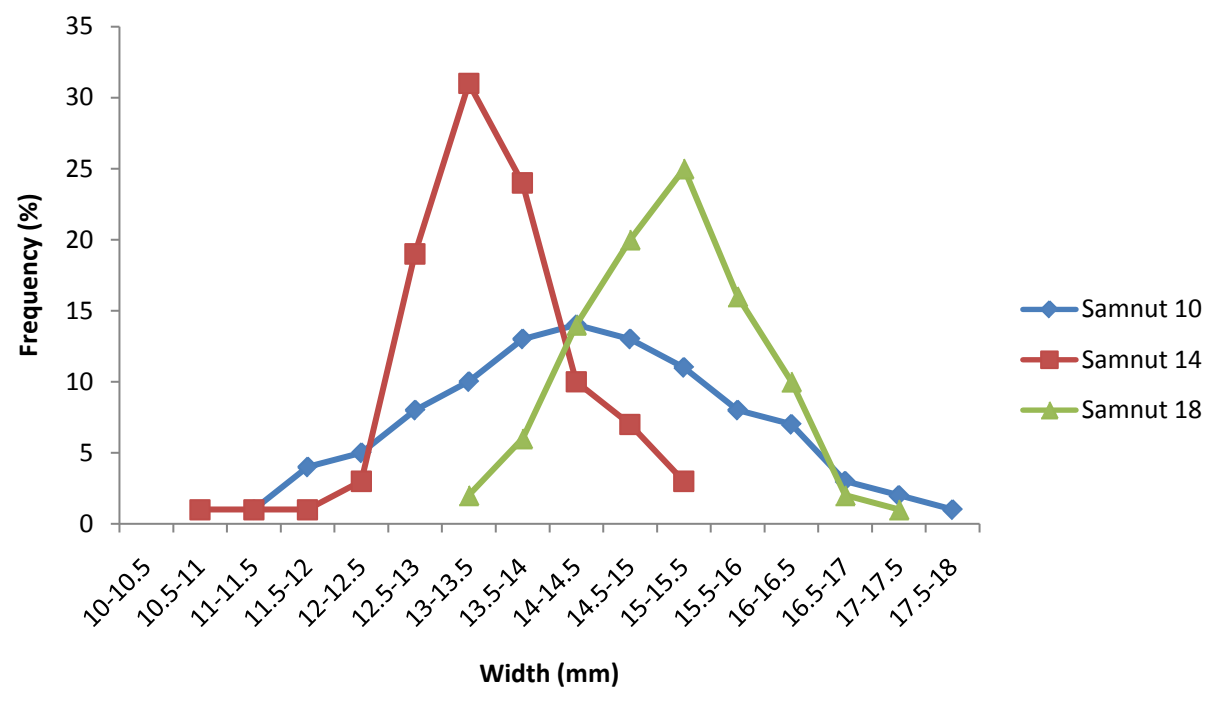

Figure 4. Frequency distribution curve for the widths of the selected groundnut varieties. 


\section{$12.99 \mathrm{~mm}$.}

Analyzing the range of values suggests that two sieves would be constructed for the grader. The sieves constructed therefore, have the following dimension: for the grader; sieve A has $50 \mathrm{~mm} \times 15.99 \mathrm{~mm}$ while sieve B: $50 \mathrm{~mm} \times 12.99 \mathrm{~mm}$.

While in operation, groundnut pods whose major diameter falls over $15.99 \mathrm{~mm}$ were retained on sieve A. Pods whose major diameters are less than $15.99 \mathrm{~mm}$ are allowed to pass through the sieve to the next sieve whose diameter was $13 \mathrm{~mm}$. Here, pods with diameters between $15.99 \mathrm{~mm}$ and $13 \mathrm{~mm}$ are retained and graded as grade II. Finally, pods whose diameters were less than $13 \mathrm{~mm}$ (12.99 $\mathrm{mm}$ and below) were collected at the bottom tray as grade III.

\subsection{Results of Grading Groundnut In-Shell}

Analyses of the results obtained for grading the three varieties of groundnut in-shell were given in Table 2. The means and standard deviations at $95 \%$ confidence limits range within each grade were computed. In all cases, the differences between the dimensional ranges of all the grades were very small. The maximum ranges within each grade when all the varieties were considered were: grade I $-15.81 \mathrm{~mm}$ to $18.05 \mathrm{~mm}$, grade II $-12.44 \mathrm{~mm}$ to $15.78 \mathrm{~mm}$ and grade III $-10.60 \mathrm{~mm}$ to $13.30 \mathrm{~mm}$. It was noted that only Samnut 10 variety that has all the three grades among the considered varieties. Samnut 14 do not have grade I while Samnut 18 that does not have grade III. The samples of each grade obtained are shown in Plate 3 . The standard deviations of all the grades of the selected varieties are found to be less than one. This means that the differences between their ranges of values are not much. It was noted that the smaller the standard deviation, the higher the degree of uniformity in the observations and the homogeneity in the series [9].

\section{Conclusion}

A groundnut in-shell grader has been designed, developed and evaluated. It has a rated capacity of $224 \mathrm{th}^{-1}$. The maximum ranges within each grade when all the varieties were considered were: grade $\mathrm{I}-15.81 \mathrm{~mm}$ to 18.05 $\mathrm{mm}$, grade II-12.44 $\mathrm{mm}$ to $15.78 \mathrm{~mm}$ and grade III-10.60 $\mathrm{mm}$ to $13.30 \mathrm{~mm}$. Of the three varieties considered, only SAMNUT 10 (Figure 5) was found to have the three grades. SAMNUT 14 do not have grade I while

Table 1. Means and standard deviations of length and width of selected groundnut varieties.

\begin{tabular}{ccccc}
\hline \multirow{2}{*}{ Groundnut Variety } & \multicolumn{2}{c}{ Length } & \multicolumn{2}{c}{ Width } \\
\cline { 2 - 5 } & Mean (mm) & Standard Deviation (mm) & Mean (mm) & Standard Deviation (mm) \\
\hline Samnut 10 & 33.22 & 5.97 & 14.34 & 1.45 \\
Samnut 14 & 25.89 & 2.00 & 13.44 & 0.78 \\
Samnut 18 & 30.01 & 1.97 & 15.11 & 0.82 \\
\hline
\end{tabular}

Table 2. Performance test of the groundnut grader.

\begin{tabular}{cccccc}
\hline Groundnut Variety & Grade & No. Observed & Mean & Standard Deviation & 95\% Limit \\
\hline \multirow{2}{*}{ Samnut 10 } & I & 100 & 16.93 & 0.57 & $15.81-18.05$ \\
& II & 100 & 14.81 & 0.84 & $13.16-16.46$ \\
& III & 100 & 11.84 & 0.51 & $10.84-12.84$ \\
Samnut 14 & I & - & - & - & - \\
& II & 100 & 14.11 & 0.85 & $12.44-15.78$ \\
& III & 100 & 11.95 & 0.69 & $10.60-13.30$ \\
Samnut 18 & I & 100 & 16.48 & 0.38 & $15.74-17.22$ \\
& II & 100 & 14.83 & $-13.43-16.26$ \\
\hline
\end{tabular}




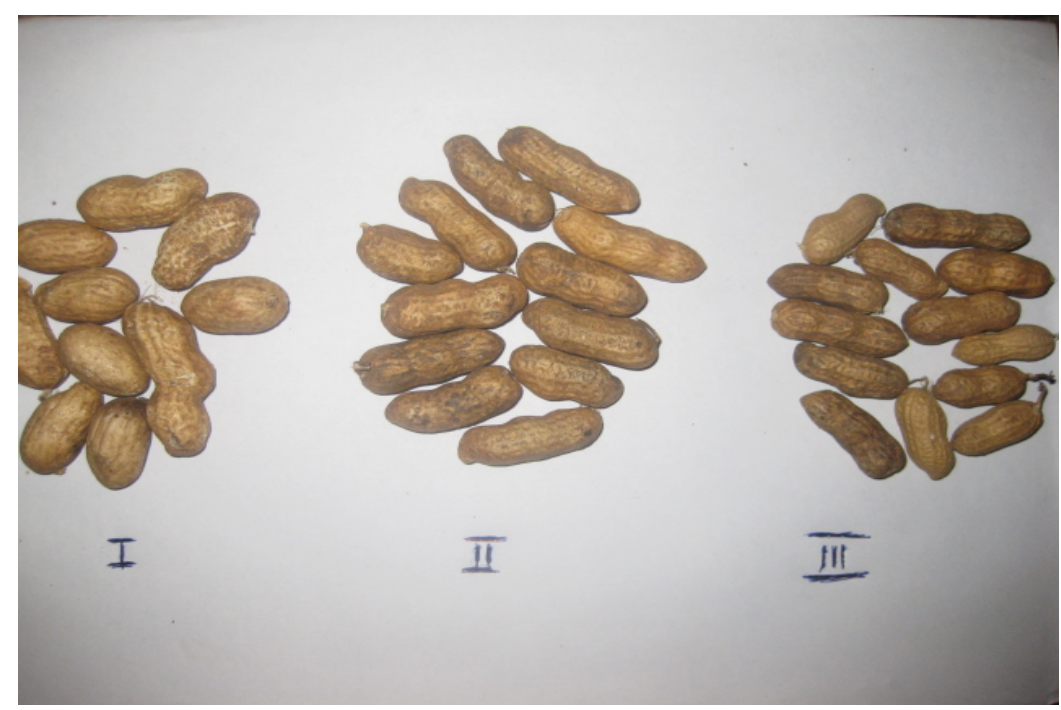

Figure 5. Grades of groundnut in-shell obtained from the grader (SAMNUT 10).

SAMNUT 18 that does not have grade III. Grading is thus an improvement in groundnut products for a qualitative output. It is crucial because of its potential to regain and increase export earnings. Such improvements also guarantee sustainability of its farming systems in Nigeria and many producing countries where it plays a key role in their agriculture-dependent economies. This will impact on rural employment, trade and purchasing power for smallholder farming families, strengthen the economic capacity of women and improve household nutrition. It will also increase the net income and foreign exchange of such countries.

\section{References}

[1] Ntare, B.R., Diallo, A.T., Ndjeunga, J. and Waliyar, F. (2008) Groundnut Seed production Manual. International Crops Research Institute for the Semi-Arid Tropics (ICRISAT), Patancher, $20 \mathrm{p}$.

[2] Whitaker, T.B., Dorner, J.W., Lamb, M., and Slate, A.B. (2005) The Effect of Sorting Farmers' Stock Peanuts by Size and Color on Partitioning Aflatoxin into Various Shelled Peanut Grade Sizes. Peanut Science, 32, 103-118. http://dx.doi.org/10.3146/0095-3679(2005)32[103:TEOSFS]2.0.CO;2

[3] Chapin, J.W. and Thomas, J.S. (2004) Peanut Money-Maker Production Guide-2004. Clemson Extension and South Carolina Peanut Board, Blackville.

[4] Mohsenin, N.N. (1986) Physical Properties of Plant and Animal Materials, Seconded. Gordon and Breach, Science Publishers Inc., New York, 58-76.

[5] Oje, K. (1993) Some Engineering Properties of Thevetia Nut. Journal of Agricultural Engineering and Technology, 1, 38-45.

[6] Olaniyan, M.A. and Oje, K. (1999) Viscoelastic Behaviour of Shea Nuts under Application of Force. 21st Annual Conference of the Nigerian Institution of Agricultural Engineering (NIAE), Bauchi, Nigeria.

[7] Firouzi, S.M., Vishgaei, N.S. and Kariami, B. (2009) Some Physical Properties of Groundnut (Aracishypogaea L.) as a Function of Moisture Content. American-Eurasian Journal Agriculture and Environmental Science, 6, 675-679.

[8] Galedar, M.N., Jafari, A. and Tabatabaeefa, A. (2008) Some Physical Properties of Wild Pistachio Nut Andkernel as a Function of Moisture Content. Journal of Physics and Environmental and Agricultural Sciences, 22, 117-124.

[9] Sykes, A.O. (2009) An Introduction to Regression Analysis. The Inaugural Coase Lecture, Professor of Law, The Law School, University of Chicago, Chicago. 


\section{Appendix I}

Schematic Illustration of the Groundnut In-Shell Grader

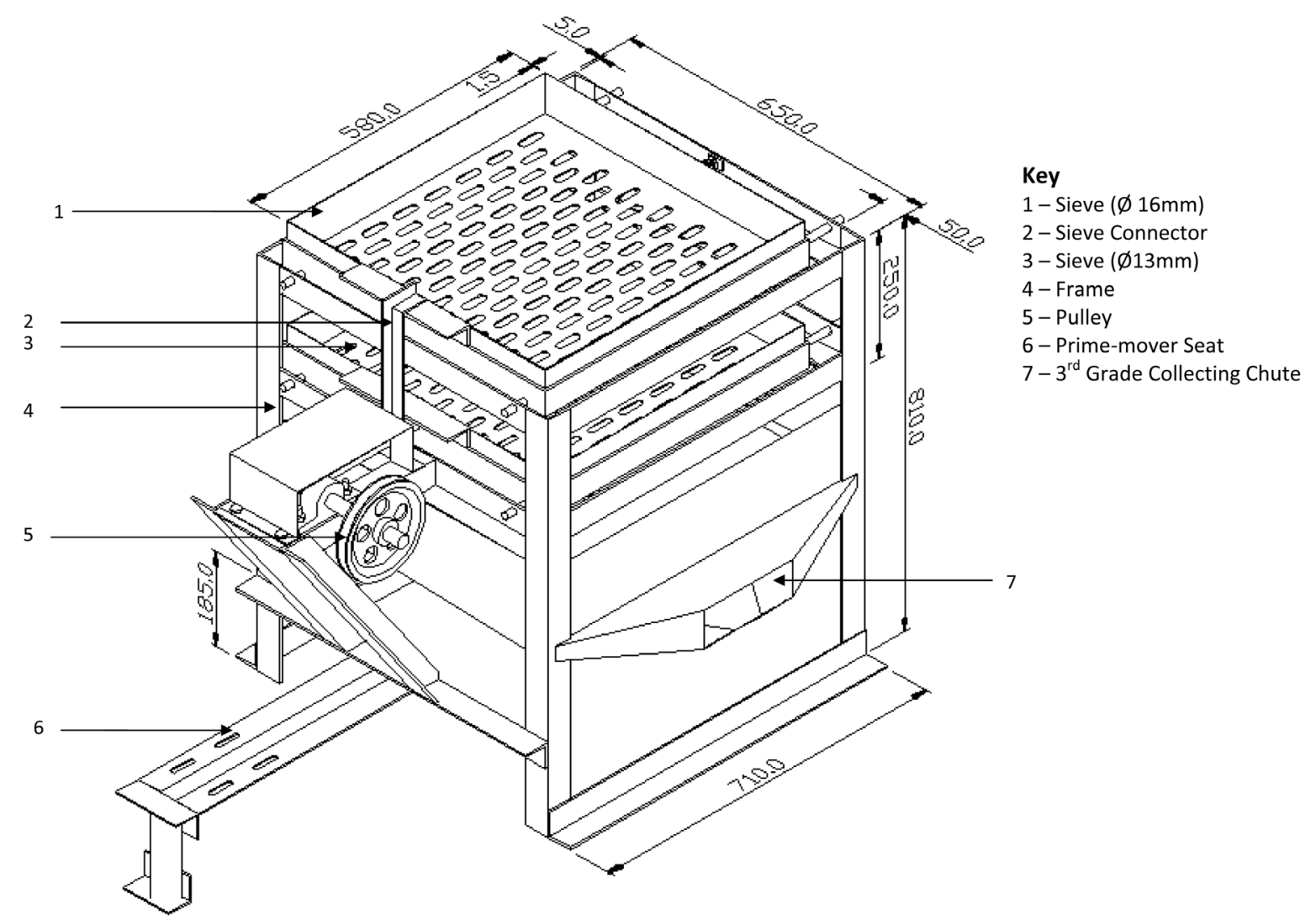

Isometric Projection of Groundnut Grader 
Scientific Research Publishing (SCIRP) is one of the largest Open Access journal publishers. It is currently publishing more than 200 open access, online, peer-reviewed journals covering a wide range of academic disciplines. SCIRP serves the worldwide academic communities and contributes to the progress and application of science with its publication.

Other selected journals from SCIRP are listed as below. Submit your manuscript to us via either submit@scirp.org or Online Submission Portal.
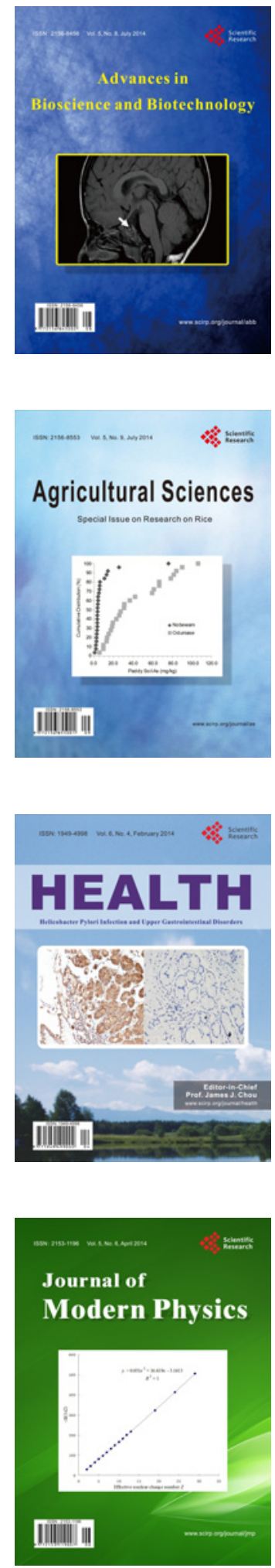
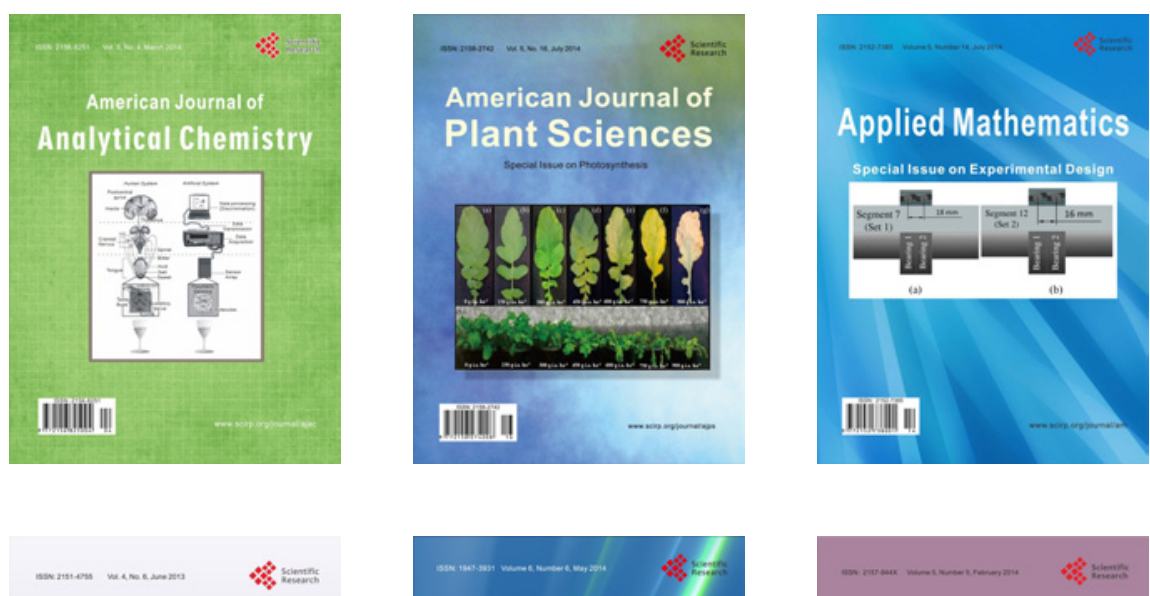

Creative Education
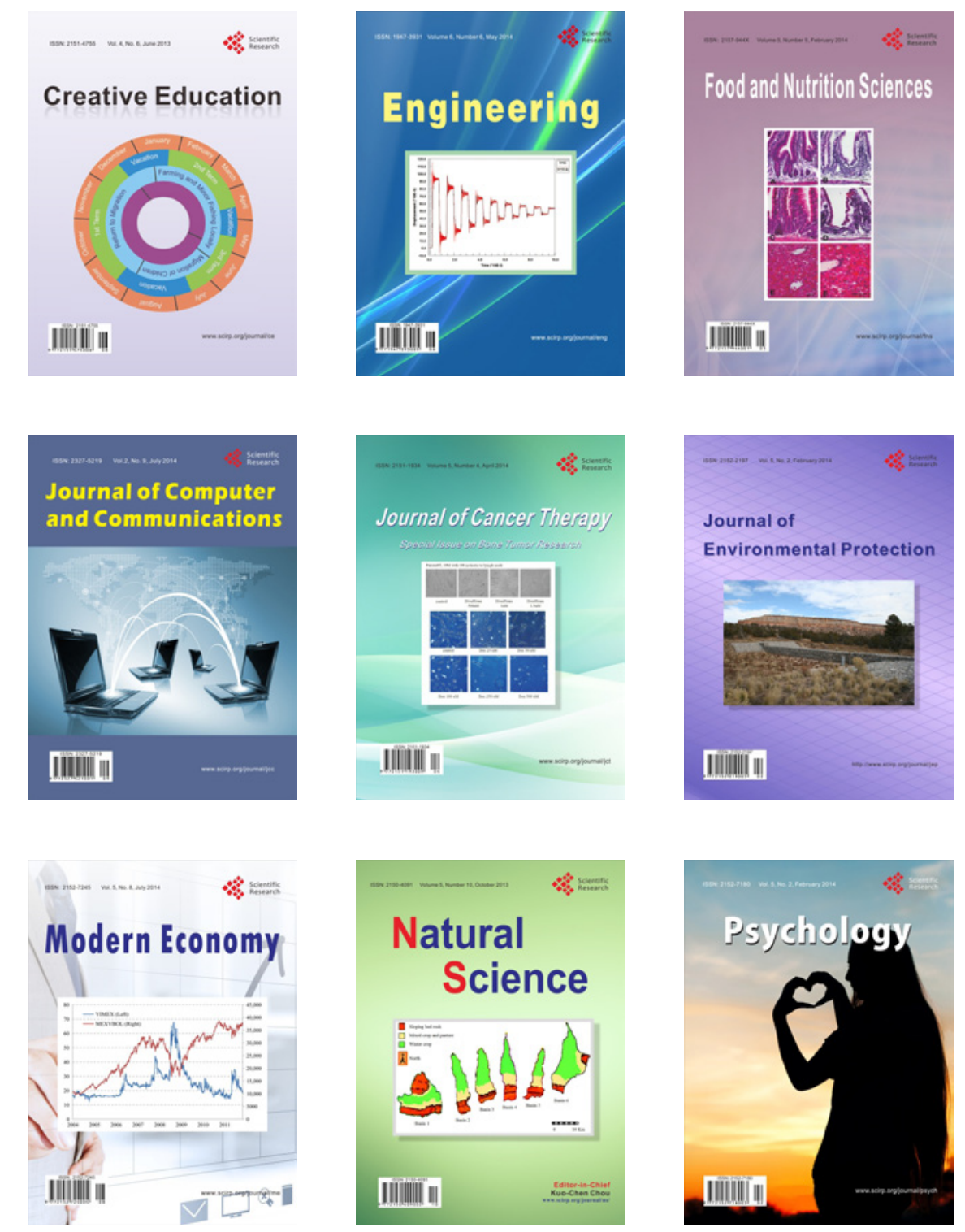